\title{
Hotplate Magnetic Stirrer Automatic Heat Control and Water Velocity Based on PID (Proportional Integral Derivative)
}

\section{Hotplate Magnetic Stirrer Pengatur Panas Otomatis dan Kecepatan Air Berbasis PID (Proportional Integral Derivative)}

\author{
Riza Alfita, Achmad Fiqhi Ibadillah, Zaifuddin*), Deni Tri Laksono \\ \{Corresponding Author: zaifuddin80@gmail.com\} \\ Program Studi Teknik Elektro, Fakultas Teknik, Universitas Trunojoyo Madura
}

\begin{abstract}
Hotplate magnetic stirrer is a laboratory tool that is used to heat or warm as well as a mix or homogenize chemical solutions. This tool is available in chemical, microbiology, and pharmaceutical laboratories. Equipped with a stirrer made of magnets (stir bar) which is used to homogenize chemical solutions. This magnetic stirrer hotplate uses an ATMega 16 microcontroller-based system. It uses an infrared temperature sensor MLX90614 to measure and monitor the temperature of the solution, starting from the start of mixing which is assisted by rotating a DC motor as a stirring device until the liquid is mixed or homogeneous. Homogeneous conditions are indicated by the ADC value (Analog to Digital Conversion) which is obtained constantly. If you use the automatic menu, only choose the mixing solution on the automatic menu. There are four choices for the solution speed of 400-1600 rpm with an increase of 400, there are four temperature choices, namely 30-60 degrees Celsius in increments of 10, and there is a choice of time used for stirring time at 1-30 minutes. For temperature display, stirring speed and stirring time can be seen on the LCD $20 x 4$ display.
\end{abstract}

Keywords - Atmega 16 Microcontroller; Hotplate; Infrared MLX90614; Magnetic Stirrer; Webcam Camera

\begin{abstract}
Abstrak. Hotplate magnetic stirrer adalah sebuah alat laboratorium yang digunakan untuk memanaskan atau menghangatkan sekaligus mencampurkan atau menghomogenkan larutan kimia.Alat ini terdapat di laboratorium kimia, mikrobiologi dan farmasi.Dilengkapi dengan pengaduk yang terbuat dari magnet (stir bar) yang digunakan untuk menghomogenkan larutan kimia. Hotplate magnetic stirrer ini menggunakan sistem berbasis mikrocontroller ATMega 16 menggunakan sensor suhu infrared MLX90614 untuk mengukur dan memantau suhu larutan, mulai dari awal pencampuran yang dibantu dengan perputaran motor DC sebagai alat penggerak pengaduk hingga cairan tercampur atau homogen.Kondisi homogen ditandai dengan nilai ADC (Analog to Digital Conversion) yang didapatkan konstan.Jika menggunakan menu otomatis hanya memilih pencampuran larutan yang ada pada menu otomatis. Terdapat empat pilihan kecepatan larutan 400-1600 rpm dengan kenaikan 400, terdapat empat pilihan suhu yaitu 30-60 derajat celcius dengan kenaikan 10, terdapat pilihan waktu yang digunakan untuk lama pengadukan pada 1-30 menit. Untuk tampilan suhu, kecepatan pengadukan dan waktu pengadukan dapat dilihat pada display $L C D 20 \times 4$.
\end{abstract}

Kata Kunci - Atmega 16 Microcontroller; Hotplate; Infrared MLX90614; Magnetic Stirrer; Webcam Camera

\section{Pendahuluan}

Semakin berkembangnya jaman kemajuan teknologi semakin canggih, seperti di bidang elektronika yang sangat membantu dalam dunia industri dan teknologi termasuk dunia kesehatan.Salah satu dampak positif dari kemajuan teknologi elektronika dalam dunia kesehatan salah satunya adalah alat hotplate magnetic stirrer.

Hotplate magnetic stirrer adalah alat pemanas cairan kimia atau jaringan yang biasanya terdapat di laboratorium mikrobiologi, kimia dan farmasi.Dengan pengaduk yang terbuat dari magnet (stir bar) yang digunakan untuk menghomogenkan larutan kimia agar tetap stabil dan menjaga temperatur jaringan saat pemeriksaan jaringan.Dilengkapi dengan pengaturan suhu pemanas dan kecepatan pengadukan.Untuk mengukur atau memantau suhu larutan yang dipanaskan masih menggunakan termometer.

Dari permasalahan di atas dibuat hotplate magnetic stirrer dengan pemantauan suhu larutan dapat dilakukan dengan mudah.Alat ini juga dilengkapi dengan sensor suhu infrared MLX90614 untuk mengukur suhu larutan tanpa kontak langsung dengan larutan. Dan stirrer menggunakan magnetic stirrer (stir bar) yang dimasukkan kedalam larutan kimia dalam gelas ukur dan digerakkan oleh motor DC yang dilengkapi dengan magnet sehingga dapat menggerakkan stir bar yang terdapat pada gelas kimia. Kontrol kecepatan motor DC (direct current) agar bergerak sesuai set point yang diinginkan oleh PID (proportional integral derivative) yang terdiri dari $\mathrm{Kp}$, Ki dan Kd yang nilainya sudah ditentukan agar mendapatkan nilai yang stabil. Selain itu hotplate magnetic stirrer ini dilengkapi 
dengan pemilihan larutan otomatis jika ingin menggunakan pilihan larutan otomatis cukup dengan menekan menu otomatis pada modul. Dengan adanya pengukur suhu larutan otomatis dapat membantu dan mempermudah laporan dalam mengerjakan tugasnya.

\section{Metode}

Perancangan hotplate ini dilengkapi dengan driver heater untuk mendeteksi suhu pada heater yang diletakkan pada plate.Dan dilengkapi dengan sensor thermo infrared yang dapat mengukur suhu larutan yang dipanaskan tanpa kontak langsung dengan larutan, sehingga memudahkan laporan untuk mengukur suhu larutan tanpa menggunakan termometer.

Isti'ah ira dalam penelitian tentang "Rancang Bangun Hotplate Magnetic Stirrer Berbasis Mikrokontroler Atmega8". Pada penelitian ini hotplate dilengkapi dengan pengatur suhu dan kecepatan putar yang diatur dengan menekan tombol up atau down tetapi untuk penelitian ini belum dilengkapi dengan termometer otomatis yang dapat mengukur langsung perubahan suhu pada larutan [1].

Hariza Faisal, Wildian, dan Meqorry Yusfi dalam penelitian tentang "Rancang Bangun Magnetic Stirrer Berbasis Mikrokontroler At89s52 Dengan Pengaturan Waktu Melalui Keypad”. Pada penelitian magnetic stirrer ini tidak dilengkapi hotplate dan untuk inputan nilai putaran RPM motor pengaduk masih menggunakan keypad dan tidak dilengkapi buzzer sebagai pengingat user bahwa waktu pengadukan telah selesai [2].

Irsyad Lalu Patria, Yudianingsih dan Sri Lestari (2016) dalam penelitian yang berjudul "Rancang Alat Magnetic Sitter Dengan Pengaturan Kecepatan Pengaduk Dan Pengaturan Waktu Pengadukan". Pada penelitian ini untuk motor sebagai pengaduk sebaiknya menggunakan torsi yang lebih tinggi sehingga saat motor mendapat beban maka kecepatan motor akan relatif stabil [3].

Alona Situmeang, ST., MT dan Rika Harian dalam penelitian yang berjudul "Perancangan Pengaduk Magnetik Dengan Pilihan Larutan Menggunakan Sistem Pengontrol Berbasis Arduino Uno". Pada penelitian ini pilihan yang digunakan kurang banyak menggunakan sensor LM35 sehingga sensor masih kontak langsung dengan larutan yang dicampurkan [5].

Jecson Steven Daniel Zebua, Mas Sarwoko Suraatmadja, Ahmad Qurthobi dalam penelitian yang berjudul "Perancangan Termometer Digital Tanpa Sentuhan" alat ini menggunakan sensor MLX90614 untuk membaca suhu akurasi terbaik saat membaca suhu yaitu pada jarak $15 \mathrm{~cm}$ di ruangan terbuka [6].

\section{Hotplate magnetic stirrer}

HotPlate Magnetic Stirrer adalah peralatan laboratorium yang digunakan untuk mengaduk dan memanaskan larutan satu dengan larutan lain yang bertujuan untuk membuat suatu larutan homogen dengan bantuan pengaduk batang magnet (stir bar).

Prinsip kerja HotPlate Magnetic Stirrer adalah berupa plate yang dapat dipanaskan dan hubungan antara dua magnet yaitu, magnet yang dihubungkan pada motor dan magnet (stir bar) yang dimasukkan dalam wadah gelas yang berisi larutan kimia yang ditempatkan pada atas pelat (plate). Dengan menggunakan Hot Plate Magnetic Stirrer, pencampuran larutan kimia dapat dilakukan dengan cepat, sehingga dapat menghemat waktu, tenaga dan dihasilkan larutan yang lebih homogen. Sinyal elektrik yang bisa ditunjukkan dalam unit temperatur setelah sesuai dengan variasi temperatur lingkungan. demikian thermal infrared ini sangat berguna untuk mengukur suhu pada keadaan dimana tidak ada sensor lain yang dapat digunakan dan dapat menghasilkan hasil yang akurat.

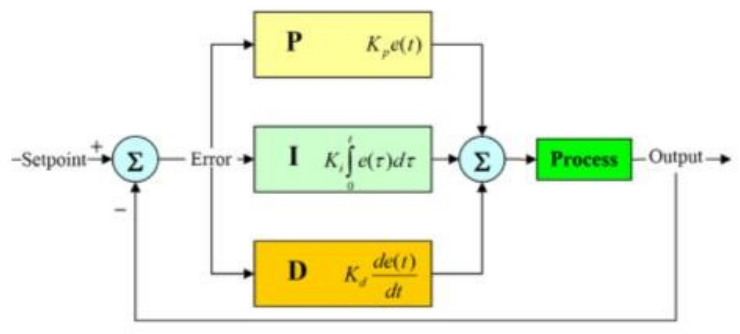

\section{Gambar 1. Sensor MLX90614}

PID (proportional integral derivative).

PID (proportional integral derivative) controller merupakan kontroller untuk menentukan kepresisian suatu sistem instrumentasi dengan karakteristik adanya umpan balik/feed back pada sistem tersebut. Komponen PID 
terdiri dari 3 jenis, yaitu proporsional, integratif, dan derivatif. Ketiganya dapat dipakai bersamaan maupun sendirisendiri, tergantung respon yang kita inginkan terhadap suatu plant.

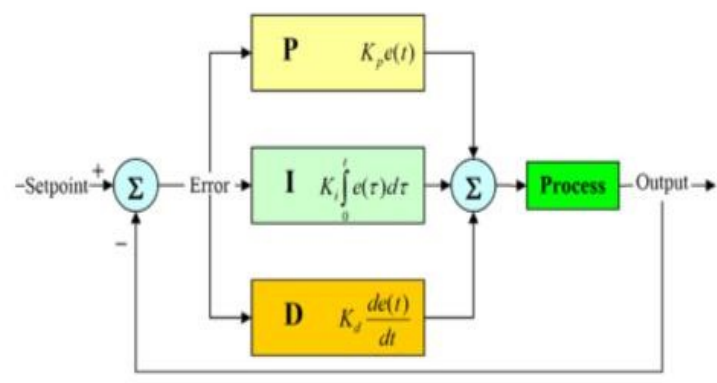

Gambar 2. Diagram PID

PWM (pulse width modulation)

Pulse Width Modulation (PWM) secara umum adalah sebuah cara memanipulasi lebar sinyal yang dinyatakan dengan pulsa dalam suatu perioda, untuk mendapatkan tegangan rata-rata yang berbeda.

Beberapa contoh aplikasi PWM adalah pemodulasian data untuk telekomunikasi, pengontrolan daya atau tegangan yang masuk ke beban, regulator tegangan, audio effect dan penguatan, serta aplikasi-aplikasi lainnya.

Aplikasi PWM berbasis mikrokontroler biasanya berupa pengendalian kecepatan motor DC, pengendalian motor servo, pengaturan nyala terang LED dan lain sebagainya. Sinyal PWM pada umumnya memiliki amplitudo dan frekuensi dasar yang tetap, namun memiliki lebar pulsa yang bervariasi. Lebar Pulsa PWM berbanding lurus dengan amplitudo sinyal asli yang belum termodulasi. Artinya, sinyal PWM memiliki frekuensi gelombang yang tetap namun duty cycle bervariasi antara $0 \%$ hingga $100 \%$.

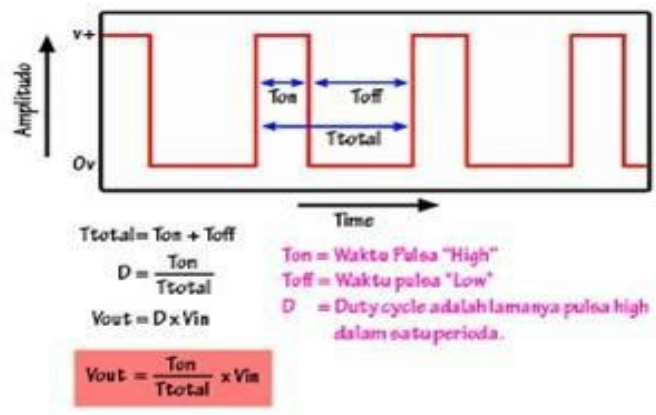

Gambar 3. Sinyal PWM dan Rumus Perhitungannya

\section{Hasil dan Pembahasan}

Prinsip kerja HotPlate Magnetic Stirrer adalah berupa plate yang dapat dipanaskan dan hubungan antara dua magnet yaitu, magnet yang dihubungkan pada motor dan magnet (stir bar) yang dimasukkan dalam wadah gelas yang berisi larutan kimia yang ditempatkan pada atas pelat (plate). Dengan menggunakan Hot Plate Magnetic Stirrer, pencampuran larutan kimia dapat dilakukan dengan cepat, sehingga dapat menghemat waktu, tenaga dan dihasilkan larutan yang lebih homogen. Dari gambar 3 di bawah dapat dilihat alat ini terdiri dari beberapa bagian mekanik yaitu plate adalah pelat panas yang digunakan untuk memanaskan larutan dimana dibawahnya terdapat heater. Tiang holder adalah tiang yang digunakan untuk menyangga sensor infrared dan camera webcam. Peredam panas adalah bahan yang terbuat dari bahan yang dapat menahan panas yang berfungsi untuk meredamkan panas dari heater agar panas tersebut tidak merusak komponen hotplate. Untuk box rangkaian sekaligus box hotplate terbuat dari bahan stainles steel yang mampu menahan panas sampai $1000^{\circ} \mathrm{C}$. Modul ini memiliki dimensi panjang $24 \mathrm{~cm}$, lebar $26 \mathrm{~cm}$ dan tinggi $9 \mathrm{~cm}$ untuk papan tombol memiliki lebar $6 \mathrm{~cm}$. Dan untuk plate mempunyai dimensi panjang $18 \mathrm{~cm}$ dan lebar $16 \mathrm{~cm}$ 


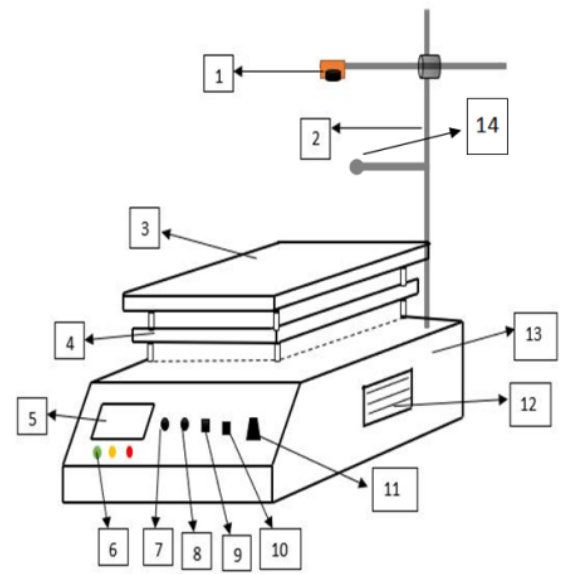

Gambar 4. Diagram Mekanik

\section{A. Flowchart}

Dari gambar di bawah ini terlihat bahwa pada rancang bangun hotplate magnetic stirrer tersebut dilengkapi dengan sensor infrared MLX90614 yang berfungsi sebagai pendeteksi suhu pada larutan kimia yang sedang dipanaskan atau berfungsi sebagai thermometer namun tanpa menyentuh atau kontak langsung dengan larutan.:

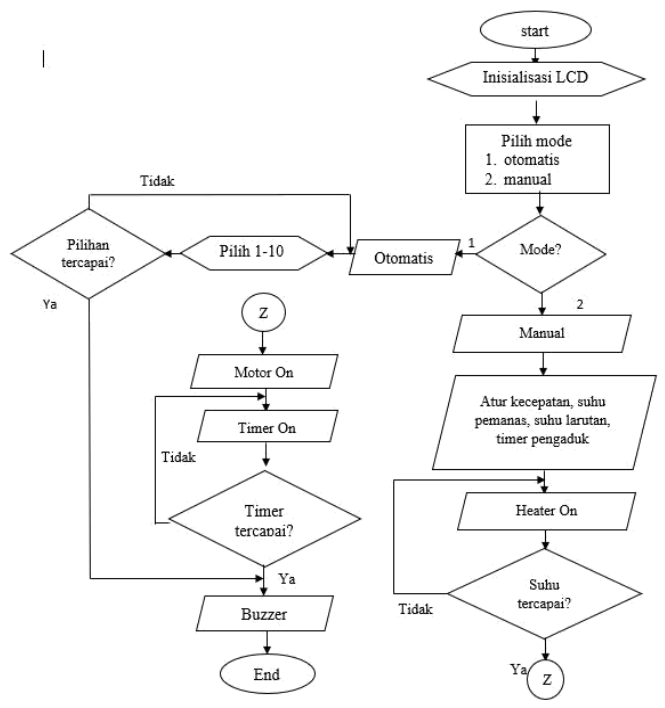

Gambar 5. Flowchart

Proses pertama yaitu inisialisasi LCD serta menampilkan mode yang ingin digunakan. LCD akan menampilkan pilih, mode 1. tomatis dan mode 2 manual. Cara kerja dari mode tersebut berbeda jika user memilih mode otomatis maka tinggal memilih data larutan yang disediakan modul, terdapat 10 data pencampuran larutan.

\section{B. Cara pengoperasian hotplate magnetic stirrer}

1) Colokkan catu datu daya ke tegangan 220 volt kemudian tekan tombol power hingga LCD nyala muncul tampilan menu pada LCD dan tampilannya seperti pada gambar 6 untuk memilih menu gunakan tombol UP dan SET-UP untuk memilih pilihan menu yang diinginkan.

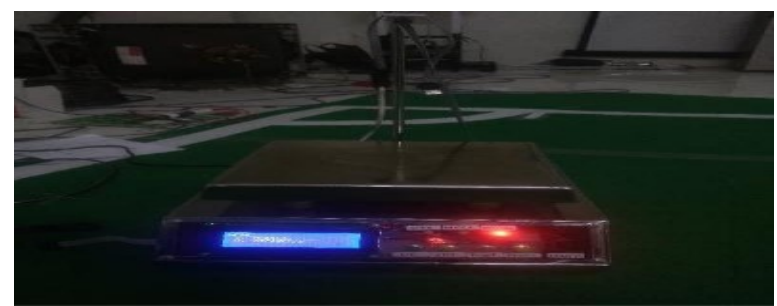


Gambar 6.Tampilan Menu Hotplate Magnetic Stirrer

2) Jika memilih menu otomatis maka tampilan LCD seperti pada gambar 7 untuk menu otomatis tinggal memilih larutan yang ingin dicampurkan dengan menggunakan tombol UP jika ingin memulai proses tekan tombol START.

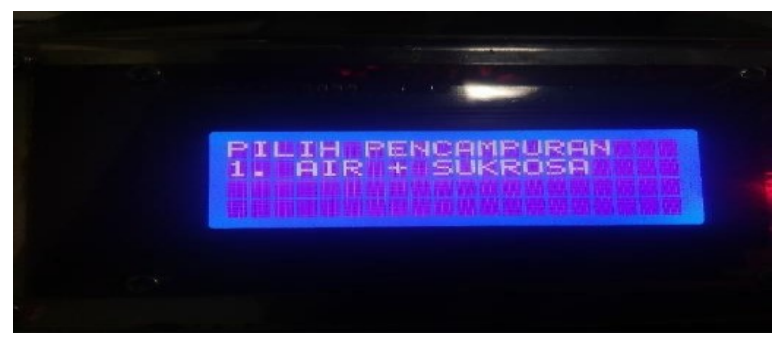

Gambar 7. Tampilan Menu Otomatis

\section{Hasil tuning PID}

Pengaturan kecepatan motor dapat menggunakan metode pengaturan kecepatan menggunakan PWM (Pulse Width Modulation), yaitu metode ini merubah nilai duty cycle pada driver motor, maka tegangan yang akan dialirkan pada motor dapat diatur, PWM pada pengujian ini menggunakan timer 0 pada mikrokontroller dengan resolusi 8 bit $(0 \mathrm{~s} / \mathrm{d}$ 255). Pengujian dilakukan untuk menerapkan metode PID (Proporsional, Integral, dan Derivative) untuk memperbaiki nilai kecepatan terhadap nilai eror pada system yang diperoleh dari nilai antara set point terhadap present value rpm motor. Dalam pengujian ini akan menggunakan RPM 400 untuk menentukan nilai $\mathrm{Kp}, \mathrm{Ki}$, dan Kd dengan cara tuning manual menggunakan metode kedua aturan Zeiger dan Nichol.

\section{Hasil pengukuran suhu}

Pada pengukuran ini menggunakan alat kalibrator thermometer digital TP101 dan sensor suhu MLX90614 diletakkan dengan jarak $3 \mathrm{~cm}$ dari gelas kimia.

Tabel 1. Hasil pengukuran suhu

\begin{tabular}{ccccc}
\hline \multirow{2}{*}{$\begin{array}{c}\text { Percobaan } \\
\text { ke }\end{array}$} & $\mathbf{4}$ & \multicolumn{4}{c}{ Suhu } \\
\cline { 2 - 5 } & $\mathbf{3 0}$ & $\mathbf{4 0}$ & $\mathbf{5 0}$ & $\mathbf{6 0}$ \\
\hline 1 & 30,1 & 40,5 & 50,1 & 60,6 \\
2 & 29,8 & 40,1 & 50,1 & 60,2 \\
3 & 29,9 & 39,9 & 50,2 & 60,5 \\
4 & 30,0 & 39,7 & 50,5 & 59,2 \\
5 & 30,6 & 39,6 & 50,2 & 60,5 \\
Rata-rata & 29,40 & 39,96 & 50,22 & 60,4 \\
Simpangan & 0,6 & 0,04 & 0,22 & 0,4 \\
Error & $2 \%$ & $0,1 \%$ & $0,44 \%$ & $1 \%$ \\
\hline
\end{tabular}

\section{KESIMPULAN}

Hoplace ini sangat membantu para medis untuk menjalankan percobaan terhadap pencampuran zat kimia. Pada percobaan rpm motor diperoleh error tertinggi pada nilai rpm 400 dengan nilai error $1.085 \%$ dan rpm dengan nilai terendah pada rpm 800 dengan nilai error $0.195 \%$. Dari percobaan suhu diperoleh error tertinggi pada nilai suhu 30 dengan nilai error $2 \%$ dan nilai error terendah terdapat pada suhu 40 dengan nilai error $=0,1 \%$. Dari percobaan timer tidak diperoleh error atau error $0 \%$ dengan membandingkan dengan stopwatch karena untuk timer menggunakan modul RTC (real-time clock). 


\section{REFERENSI}

[1] A. Labor, "Pengertian dan Fungsi dari hotplate," Alat Labor. [Online]. Available: https://www.alatlabor.com/article/detail/221/pengertian-dan-fungsi-dari-hotplate-. [Accessed: Sep. 05, 2018]

[2] M. Nasrullah, "HOT PLATE MAGNETIC STIRRER DENGAN PENGENDALI BERBASIS MICROCONTROLLER ATMega16," D3 Thesis, Politeknik Muhammadiyah Yogyakarta, Yogyakarta, 2016 [Online]. Available: http://repository.umy.ac.id/handle/123456789/4877. [Accessed: Sep. 08, 2018]

[3] K. ANWAR, "PENGENDALIAN KECEPATAN MOTOR DC DENGAN KONTROL PID BERBASIS MIKROKONTROLER ATMEGA 8535," Undergraduate Thesis, Universitas Muhammadiyah Surakarta, Surakarta, 2011 [Online]. Available: http://eprints.ums.ac.id/14575/

[4] B. R. Copeland, "The Design of PID Controllers using Ziegler Nichols Tuning," 2008.

[5] R. D. A. Manik, "Laporan Resmi Kimia Dasar 1," Universitas Mulawarman, Samarinda, Practicum Report, 2014 [Online]. Available: https://www.academia.edu/16761826/Laporan_Resmi_Kimia_Dasar_1

[6] M. A. Rahman, "Rancang Bangun Hotplate Stirrer Magnetik Terkendali Temperatur ${ }^{-}$dan Kecepatan Pengaduk," Undergraduate Thesis, University of Indonesia, Depok, 2011.

[7] H. Faisal and M. Yusfi, "Rancang Bangun Magnetic Stirrer Berbasis Mikrokontroler AT89S52 Dengan Pengaturan Waktu Melalui Keypad," Jurnal Fisika UNAND, vol. 2, no. 3, pp. 148-154, 2013.

[8] A. Krisnatal, "STUDI SISTEM PENGADUK BERBASIS MAGNET DAN PEMANAS FLUIDA DENGAN MENGGUNAKAN MIKROKONTROLER,” Undergraduate Thesis, Universitas Telkom, 2017 [Online]. Available: https://repository.telkomuniversity.ac.id/pustaka/137521/studi-sistem-pengaduk-berbasis-magnetdan-pemanas-fluida-dengan-menggunakan-mikrokontroler.html

[9] I. Isti'anah, "RANCANG BANGUN HOT PLATE MAGNETIC STIRRER BERBASIS MIKROKONTROLER ATMEGA8," Undergraduate Thesis, Universitas Muhammadiyah Yogyakarta, Yogyakarta, 2017 [Online]. Available: http://repository.umy.ac.id/handle/123456789/16001

[10] L. P. Irsyad, Yudianingsih, and S. Lestari, "Perancangan Alat Magnetic Stirrer Dengan Pengaturan Kecepatan Pengaduk Dan Pengaturan Waktu Pengadukan," JURNAL SAINS DAN KOMPUTER, vol. 1, no. 2, 2016, doi: 10.1233/jurnal. [Online]. Available: https://journal.ukrim.ac.id/index.php/JIF/article/view/197. [Accessed: Jan. $08,2023]$ 